\title{
O PROGRAMA DE INTEGRIDADE E A RESPONSABILIDADE ADMINISTRATIVA DA PESSOA JURÍDICA NA LEI 12.846/13 (LEI ANTICORRUPÇÃO) - NOVOS TEMPOS
}

THE CORPORATE COMPLIANCE PROGRAM AND THE CORPORATE LIABILITY REGARDING THE LAW 12.846/13 (ANTICORRUPTION LAW) - NEW TIMES

Lene Revoredo GOUVEIA ${ }^{1}$

ISSUE DOI: $10.21207 / 1983.4225 .605$

\begin{abstract}
RESUMO
A Lei Federal 12.846, de 1o agosto de 2013, regulamentada pelo Decreto Federal 8.420 de 18 de março de 2015, vem suprir uma importante lacuna em nosso Ordenamento Jurídico, no que toca à Responsabilização das Pessoas Jurídicas, pela prática de atos lesivos contra a Administração Pública do país. Ela estabelece que tal responsabilização se dá nas áreas civil e administrativa e é do tipo objetiva, ou seja, não se perquire a presença de culpa das Organizações Empresariais infratoras, que vêm recebendo, por seu turno, multas altíssimas pela prática de tais atos, acrescidas de outras referentes aos danos exponenciais causados à Administração Pública. Previsto está, nessa Lei, e de forma muito clara em seu Regulamento, a importância da existência de um Programa de Integridade, também conhecido com Gestão de Compliance, a ser apresentado pelas Organizações Empresariais infratoras.
\end{abstract}

\footnotetext{
${ }^{1}$ Doutorado em Educação (2007) - UFRJ. Doutorado em Medicina (1995) - UFRJ. Mestrado em Medicina (1976) - UERJ. Graduação em Medicina e Direito. Médica. Advogada. Especialização em Direito Civil Geral (2014) - Universidade ANHANGUERA - UNIDERP. Especialização em Direito Constitucional (2016) - Universidade ANHANGUERA - UNIDERP. Professora Assistente da Faculdade Presbiteriana Mackenzie-Rio. Ex-Professora Assistente da Faculdade de Ciências Médicas - UERJ. Ex-Professora Adjunto da Faculdade de Medicina - UFRJ. Especialização em Perícia Criminal (2013) - UCB. Especialização em Acupuntura (1998) - IARJ. Especialização em História da Arte e Arquitetura no Brasil (1997) - PUC/RJ. http://lattes.cnpq.br/1910881289109463.
} 
Trata-se de um Programa que vem estabelecer uma nova cultura organizacional empresarial, uma cultura firmemente apoiada na ética e na transparência das atividades empresariais. De evidente importância é o fato de que a existência de um Programa de Integridade, efetivo e eficaz, é condição observada na celebração de um Acordo de Leniência com a Organização Empresarial ofensora, bem assim na aplicação das sanções, ocasião em que a referida Organização poderá obter uma sensível mitigação no valor das multas significativas que lhe serão aplicadas.

Palavras-chave: Lei Federal 12846/13 - Decreto Federal 8420/15 - Programa de Integridade Compliance - Responsabilidade Administrativa Objetiva - pessoa jurídica - atos lesivos - severas sanções administrativas.

\begin{abstract}
The Federal Law 12.846 from August 1st, 2013, that has become effective by the Federal Act 8420 from March 18, 2015, is very important in creating an effective Compliance Program, that is a critical component of a Company's policies, in order to detect and prevent corrupting acts. The Program implies that each Compliance Program is unique for each company. It establishes the particular risks for each business and, imperatively, no one-size-fits-all Program. Until 2013, a specific law regarding violation by any company didn't exist. The new Brazilian law sets the Corporate liability objectively. It doesn't necessarily need the presence of the company's fault in the practice of violating actions, since it is the object liability. Besides, this Law is very clear in requiring the company's ethical business practices, because it is absolutely necessary the foundation of a strong ethical culture in each company. An effective Corporate Compliance Program, that educates employees as to what is and isn't accepted prevents eventual violations and if they do occur, it would be possible to remediate them quickly. Also, it would permit mitigation, among others severe punishments, such as extremely high fines.
\end{abstract}

Keywords: Federal Law 12846/13 - Federal Act 8420/15 - Corporate Compliance Program Compliance - Corporate Liability - corrupting acts - extremely high fines.

\title{
1 INTRODUÇÃO
}

"Afinal, que lei é essa?" "Para que mais uma lei nesse país?" "Todos são corruptos!" "Trabalho muito, pago todos os impostos e não tenho o básico!" "Isso nunca vai mudar!" "Esse país não tem jeito!"

Ouvimos tais dizeres todos os dias e sentimos a raiva, a impotência e, principalmente, a desesperança que eles transmitem. Contudo, há muita coisa positiva acontecendo! Quando, em que momentos, podíamos pensar que veríamos em nosso país, altos executivos, proprietários de grandes Organizações Empresariais, componentes de um Olimpo exclusivo, descendo a um nível muito mais baixo que o de meros mortais: a prisão? Quando sequer imaginamos que políticos, "pessoas especiais". habitantes de Pasárgada, estariam frente a magistrados de $1^{\circ}$ grau, dando depoimentos, sendo condenados e recolhidos à cadeia? Quando esperaríamos ver, até mesmo um ex-presidente da república, condenado e recolhido a uma cela na prisão? 
Também ouvimos que quantias, extremamente altas, vêm retornando ao país, enquanto outros valores, igualmente altos, estão sendo pagos pelos envolvidos! Quando tínhamos visto algo assim antes?

Por que será que isso vem acontecendo?

Os tempos realmente mudaram e, em $1^{\circ}$ de agosto de 2013, surgiu no Ordenamento Jurídico brasileiro a Lei 12.846, a Lei Anticorrupção, que entrou em vigor em 29 de janeiro de 2015. Não é apenas mais uma Lei, é uma Lei diferente, é uma Lei que vem atacar a parte mais vulnerável do agente infrator, o bolso!

A Lei 12.846/2013 dispõe sobre a responsabilidade civil e administrativa objetiva da pessoa jurídica. Ora, na área civilista trata-se daquela responsabilidade em que não se perquire a culpa, apenas se estabelece o nexo causal entre o ato ilícito e o dano ou prejuízo causado à vítima, dano este que pode ser, inclusive, apenas moral e que deverá ser indenizado. Se não existe o dano, não há o que indenizar. Entretanto, na seara administrativa, à luz dessa nova Lei, a responsabilidade objetiva da pessoa jurídica traz uma grande novidade, que, de tão importante e, mesmo, fundamental, no que toca à punição da pessoa jurídica pela prática do ato lesivo à Administração Pública, vem permitindo ao Judiciário exercer seu poder judicante, com sentenças pesadas como vimos observando, mormente entre os magistrados de $1^{\circ}$ grau. As multas são tão vultosas que podem chegar a até $20 \%$ do faturamento bruto da Organização no semestre anterior!

Mais ainda, as Organizações Empresariais ofensoras estão sujeitas a sanções representadas pelas inscrições no CNEIS (Cadastro Nacional das Empresas Inidôneas e Suspensas), bem assim no CNEP (Cadastro Nacional das Empresas Punidas), sem prejuízo da extensa publicidade obrigatória, disposta pela mesma Lei 12.846/13.

E ainda não acabou! Poderá a Organização Empresarial infratora ser alvo de responsabilização na esfera judicial, em que, se condenada, poderá vir a sofrer entre outras sanções, até mesmo sua dissolução compulsória! O que irá, então, restar de seu nome, de seu prestígio, de seu valor no mercado, podendo até mesmo deixar de existir? Seria a sua Pena de Morte!

Trata-se, sem dúvida, de Lei extremamente gravosa, cujos resultados de sua aplicação têm sido mostrados diuturnamente. Entretanto, por outro lado, tendo conhecimento de tais perdas, as pessoas jurídicas entenderão que mais importante que precisar buscar um acordo de 
leniência ou de delação premiada, será o da implantação de um Programa de Integridade efetivo, Programa esse que, com o objetivo principal de prevenir a ocorrência de tais atos lesivos, mesmo que assim ainda ocorram, permitirá que sejam detectados e corrigidos, podendo assim ser a pessoa jurídica beneficiada com a mitigação das penas.

Dessa forma, salvo melhor juízo, conhecer o que significa um Programa de Integridade, também conhecido como Gestão de Compliance, quais os seus objetivos, como deverá ser aplicado, o que dele poderá ser esperado, precisa ser do conhecimento da sociedade como um todo, de se ver que a Lei 7.753/17 do Estado do Rio de Janeiro, em vigor desde 17 de novembro de 2017, em seu Art. 1ㅜ, "estabelece a exigência do Programa de Integridade às empresas que celebrarem contrato, consórcio, convênios, concessão ou parceria público-privada com a administração pública direta, indireta e fundacional do Estado do Rio de Janeiro ...) (grifo meu) Podemos avaliar, em assim sendo, apenas da leitura desse dispositivo, o que passam a esperar as pessoas jurídicas no Estado do Rio de Janeiro, no exercício de suas atividades empresariais.

Eis que iniciamos nesse trabalho, apreciando algumas noções básicas sobre o imprescindível Programa de Integridade e, logo após, dedicar-nos-emos à discussão do que efetivamente, a nosso ver, data venia, trouxe de grande novidade a Lei 12.846/13 e seu Decreto Regulamentar $8420 / 15$.

Verdadeiramente, a realidade está mudando. Cremos possível que a raiva, a impotência e a desesperança cedam lugar à tranquilidade, à força e à produtividade entre nós. Bem ... Novos Tempos, não?

\section{O PROGRAMA DE INTEGRIDADE}

Também chamado de Sistema de Gestão de Compliance, ou abreviadamente, Compliance, apresenta-se como mecanismo condutor da atividade de uma organização empresarial, no cumprimento das regras legais dispostas na Lei 12.846, de 1ํ de agosto de 2013 e no Decreto Federal 8.420, de 18 de março de 2015, valendo-se, para tal, de inúmeros atos, como: avaliação dos riscos a que está exposta a organização, comprometimento da alta direção organizacional, treinamento dos funcionários em todos os seus níveis de atuação, investigação da existência 
de atos ilícitos e outros mais, com a finalidade precípua de permitir a essa organização uma existência ética e produtiva em sua atuação na sociedade.

Dessa forma, Compliance tem como finalidade prevenir, detectar e remediar os ilícitos que, porventura, venham a comprometer o atuar de uma dada Organização Empresarial e a realiza por meio de atos, que nada mais são que obrigações firmadas entre o responsável pela aplicação do Compliance e o responsável pela Organização Empresarial respectiva, à luz das regras legais. Tais atos se desenvolvem e se relacionam, lado a lado, em uma situação de interdependência, vinculados, irremediavelmente, por uma relação de cooperação, pois que nenhum está em posição superior aos demais, ao mesmo tempo em que orientados estão para a finalidade da construção efetiva de uma Organização Empresarial e, insistimos nisso, sempre em conformidade com a ordem legal.

Percebe-se, dessa forma que Compliance, como processo que é, mostra-se como um ser dinâmico, um organismo vivo, composto de inúmeros atos obrigacionais, praticados com uma finalidade ética e justa, que podem sofrer modificações pontuais no desenvolver da atividade empresarial, conforme necessidades específicas, mas que permanecem em uma situação de cooperação entre si, sem que percam sua independência e, nunca é demais repetir, em conformidade sempre com o que determinam as regras legais.

Tal caracterização do Programa de Compliance vem afastar possíveis ideias mais simplistas, de que basta um Código de Ética distribuído aos diversos departamentos da Organização; uma reunião inicial dos setores mais importantes com o Compliance Officer; arranjo de uma sala equipada com computadores; alguns sorrisos e apertos de mão e todos poderão descansar com a sensação do dever cumprido. Compliance é muitíssimo mais do que isso, envolve, na verdade, um conhecimento efetivo de todos os que na Organização trabalham, desde o chamado "chão de fábrica" até a Alta Administração, esta, necessariamente, com o conhecimento e o comprometimento efetivo com todo o Programa de Compliance. É ela que se constituirá no exemplo a ser seguido por todos que trabalham na dada Organização. E estes precisarão conhecer completamente esse Programa, nele serem treinados, treinamento efetivo e continuado, ocasião em que deverão ser esclarecidos de todo o seu funcionamento, do porquê de sua existência, de quais resultados deverão ser apresentados, em quê estes resultados beneficiam a todos, como se portar ao detectarem a produção de atos ilícitos e como serão protegidos por tais denúncias. Todos esse desenrolar, como se percebe, demonstra 
que o Programa de Compliance não se esgota em si mesmo, ele é um instituto em permanente evolução, um continuum de práticas obrigacionais, atualizadas e fiscalizadas a cada momento.

Dessa feita, entende-se que o programa de Compliance, no que tange à sua finalidade, reveste-se de uma visão muito mais abrangente que apenas a de conduzir uma Organização Empresarial na execução de suas atividades, em prol da consolidação de sua posição no mercado, por meio de uma conduta ética em conformidade com a Lei. Indubitavelmente, há em sua filosofia uma intenção muito clara de modificar a cultura da Organização, cultura essa que transcende o nível mercadológico para alcançar a alma das pessoas, seus conceitos éticos e morais no tratamento da coisa pública, de uma aceitação mais democrática das diferenças, bem assim o desejo e o hábito de fazer a coisa certa, para que toda a sociedade possa caminhar sem os obstáculos nocivos observados na atualidade. Acreditamos mesmo que a atividade empresarial voltar-se-á cada vez mais para a prevenção de problemas. "Isto é, a atuação corporativa deverá se concentrar em momento muito aquém da judicialização ou do agravamento de irregularidades. (MUDROVITSCH, R.B. \& NÓBREGA, G.P., 2019)

Embora a compreensão do Compliance tenha sido tradicionalmente "desenvolvida na seara do sistema financeiro internacional, associada à criação no ano de 1974, do Comitê de Basiléia para a supervisão bancária,..." tais programas de Compliance estão "...hoje associados aos mais diversos setores da economia...", configurando o que se conhece como "compliance ambiental, compliance trabalhista, compliance tributário e, porque não, compliance anticorrupção." (RIBEIRO, 2017: p.202)

Depreende-se, dessa forma, que a real efetividade do Compliance repousa na importância, reconhecida internacionalmente, da participação efetiva do setor privado, como prevê, expressamente, "o mais importante documento internacional sobre o tema, a Convenção das Nações Unidas contra a Corrupção”, adotada pela Assembléia Geral das Nações Unidas, em 31 de outubro de 2003 e ratificada pelo Brasil pelo Decreto 5687, em 2006, em que a expressão entidades privadas está presente no artigo 12, em todos os seus incisos. (RIBEIRO, 2017: p. 202)

Por outro lado, observou-se que era no setor público que se encontravam as principais razões para os inúmeros escândalos observados, já que “em todos eles o dinheiro público foi o principal alvo". Dessa forma, 
tanto no setor público como no privado, passaram a existir iniciativas de melhorias da governança."(LUCHIONE \& CARNEIRO, 2017: p.87). Podemos, assim, definir uma boa governança corporativa como " $o$ conjunto de relações entre a administração de uma empresa, seu conselho de administração, seus acionistas e outras partes interessadas", como entende a Organização para a Cooperação e Desenvolvimento Econômico (OCDE)

Uma boa governança corporativa, presente no setor privado, estende-se, dessa feita, ao setor público, no dizer de LUCHIONE \& CARNEIRO, (2017: p.87-88), verbis:

“...como observância das normas de boa conduta para a Administração Pública, bem como o respeito às medidas adotadas pela lei para governar o país em questão, dentro de uma política ética e de combate à corrupção, ao suborno e às irregularidades administrativas".

Assim, é editada a Lei 13.303/16, o Estatuto das Estatais (Empresa Pública, Sociedade de Economia Mista e suas subsidiárias) que, em seu art. $6^{\circ}$, dispõe, verbis:

Art. 6-: “...deverá observar regras de governança corporativa, de transparência de estruturas, práticas de gestão de riscos e de controle interno, composição da administração e, havendo acionistas, mecanismos para sua proteção, todos constantes desta Lei." (grifo do autor)

Impende lembrar que o Brasil, a exemplo da legislação internacional, dispõe, na Lei 12.846, de $1^{\text {o }}$ de agosto de 2013 e em seu Decreto 8420/2015, art. 41, caput, no que tange à pessoa jurídica, em que consiste o Compliance Anticorrupção ou Programa de Integridade, verbis:

\footnotetext{
“... no conjunto de mecanismos e procedimentos internos de integridade auditoria e incentivo à denúncia de irregularidades e na aplicação efetiva de códigos de ética e de conduta, políticas e diretrizes com o objetivo de detectar e sanar desvios, fraudes, irregularidades e atos ilícitos praticados contra a administração pública, nacional ou estrangeira."
}

Em assim sendo, torna-se evidente o fato de que o papel fundamental na efetividade de um Programa de Compliance, em uma dada Organização, está em sua Alta Direção, que precisará mostrar o seu claro engajamento no referido Programa. Tal engajamento será expresso, por seu turno, em várias atitudes, conhecidas por todos na 
Organização, como na criação de um canal de comunicação direto com a área do Compliance, evidenciando a total independência desse último de outros setores da Organização, em suas atividades e, mais ainda, provendo a referida área de Compliance de recursos próprios, entendidos esses, não apenas com recursos financeiros, de espaço físico, de maquinário e de pessoal, como também, e principalmente, no apoio explícito e eficaz aos atos de seus integrantes, em seu relacionamento no dia a dia da empresa.

A importância da Alta Direção torna-se extremamente evidente, quando nos deparamos com a expressão "tone of the top", conceituada pela Association of Certified Fraud Examiners, USA, como: "a atmosfera ética criada no ambiente de trabalho pela liderança das organizações”, e, explicando mais claramente a autora, "fundamentada na constatação de que qualquer que seja o "tom" dado pela liderança das organizações, ele estabelece o comportamento dos demais membros de forma definitiva.". (HIDALGO:2016,p.47)

Como tem-se observado, notadamente na realidade em que vimos vivendo, é que as questões críticas vinculadas a fraudes, têm sido relacionadas, predominantemente, "a decisões advindas dos níveis superiores ("TOP”), que podem ser tomadas no sentido de obter-se bons resultados para as atividades da Organização. Dessa forma, cita a autora, verbis:

"Via de regra o comportamento fraudulento surge como reação às expectativas de responder ao mercado financeiro e ao estabelecimento de objetivos relacionados ao modelo de incentivos, fortes fatores de pressão nas organizações." (Idem, p.47)

Muito interessantes são os estudos realizados na tentativa de entender o que acontece nas organizações, que "permite, favorece e/ou estimula ações que podem romper limites éticos, levando a fraudes?" (HIDALGO: 2016, p.47). Cita a autora que podemos entender as Organizações [em geral] como "...espaços de ação politica e estratégica, em que naturalmente surgem conflitos de interesse, campo fértil para ações que podem romper os limites éticos, levando a ações fraudulentas." (Idem, p.49)

Chama ela igualmente a atenção para o fato de que os limites existentes em uma Organização, para o controle de padrões éticos e dos seus valores e para garantir que as ações os respeitem, são ditados, normalmente, por duas vertentes bastante fortes: os Sistemas de Gestão de 
Pessoas e o modelo de Governança adotado. No primeiro, “...há uma em especial que visa estabelecer de forma bastante específica os limites de atuação de cada membro da Organização: o código de conduta." (Idem, p.56) Quanto ao modelo de Governança, HIDALGO (p.56) recorre a Benjamin E. HERMALIN (2005), que estabelece que "a Governança está relacionada à forma como as organizações devem ser dirigidas"; Jean TIROLS (2001), "que advoga que o importante é a maneira como deve ser feito o monitoramento de suas estruturas: quem e como as deve dirigir"; e Gordon DONALDSON (2001), "apontando que o papel da Governança e, logo, do Conselho de Administração é também o de”, verbis:

\footnotetext{
...uma supervisão estratégica sobre a Organização que permita não só uma intervenção corretiva em caso de desvio da rota estratégica e de resultados, como também uma ação proativa antecipatória em relação a eventos de contexto. Nesse caso o Conselho de Administração exerceria um papel de auditoria estratégica como objetivo de assegurar a eficácia das decisões.
}

Com tais conceitos em mente, podemos entender melhor a enorme importância da conscientização e a consequente postura da Alta Administração, no efetivo cumprimento do Programa de Compliance pela Organização a que esse se destina.

E para que um efetivo Programa de Compliance possa ser elaborado, é imprescindível que seja feito "um diagnóstico prévio dos riscos inerentes" à Organização de que se trata, lembrando que tal análise precisa ser contínua e constante, ultrapassando mesmo o período dedicado à elaboração do referido programa, devendo, portanto, ser "refeita periodicamente", durante todo o tempo em que esse Programa estiver vigendo. (UBALDO:2017, p.124)

O que deve ser visceralmente compreendido pela Organização Empresarial é que a correta avaliação dos riscos das atividades que pratica, constitui-se em um fator de tal relevância, que a falta de entrosamento entre a confecção do Programa de Compliance e o reconhecimento dos riscos envolvidos, irá dificultar, talvez impossibilitar, o comprometimento real da referida Organização com o verdadeiro combate à corrupção que se procura atingir. RIBEIRO (2017: p.210) mostra, de maneira muito clara, os reais objetivos a serem alcançados no correto gerenciamento desses riscos, verbis: 
de garantia em relação à realização dos seus objetivos, permitindo entender os riscos que afetam a missão da Organização, alinhar o apetite dos riscos com suas estratégias, realçar o planejamento dos negócios e reduzir surpresas operacionais e perdas econômicas.

Pode-se ressaltar, dentre os fatores de risco mais observados estão aqueles referentes ao tamanho da Organização, aos inerentes às suas atividades, aos advindos das interações com os órgãos da Administração Pública, ao marco legal e regulatório e ao grau de participação de terceiros e intermediários.

Este último fator é de uma extrema importância e sua avaliação constitui-se no instituto conhecido como due diligence, em que a Organização se conscientiza de que precisa exigir dos terceiros e intermediários, com os quais se relaciona em suas atividades, o mesmo comprometimento que ela, a Organização, tem com o seu Programa de Compliance, como expõe Alexandre SERPA, ao demonstrar que due diligence é o buscar-se "entender as práticas dos terceiros, seu passado, o passado de seus administradores ou sócios, antes de se fechar acordos ou contratos com eles". (2016: p.73) Sua importância reside principalmente na avaliação de possíveis problemas anteriores, apresentados por esses stakeholders, as chamadas red flags, o que poderá afastar ou mesmo minimizar possíveis riscos na ocasião de contratar. Importante lembrar que nem todas as relações que terá a Organização Empresarial com esses contratados, poderão vir a implicar em riscos para ela, entretanto, surgindo dúvidas, deverá ser necessária a contratação de especialistas para tais avaliações, que deverão ser documentadas, com o envolvimento das áreas de Compliance e Jurídica. Evidentemente, como situações novas poderão surgir no desenrolar dessas parcerias, deverá ser estabelecido, contratualmente, em que períodos de tempo deverão ser refeitas tais avaliações. (Idem,2016:p.74)

Internamente, a Organização precisará estar vigilante quanto às atividades exercidas por seus funcionários, que, além de estarem cônscios e realmente informados sobre o Programa de Compliance, pois que, como já demonstramos, trata-se de um programa vivo, em constante e permanente evolução, igualmente compreendam que serão necessários treinamentos periódicos para todos os que na empresa trabalham e que tal conduta vem contribuir de maneira cabal para o desempenho e a segurança da Organização, bem assim para o entendimento geral de que o Programa de Compliance "não deve ser visto como um empecilho." (UBALDO:2017, p.124) Quando cuidamos dos treinamentos periódicos 
de todos os envolvidos nas diversas atividades da Organização, necessário é que nos preocupemos que todos estejam de acordo com as práticas de conduta preconizadas no Programa, que estarão orientadas por um Código de Conduta Ética e pelas Políticas da Organização, "cujas ações estão especialmente voltadas para o combate à corrupção.” (Idem, p.121)

Como um dos importantes objetivos do Programa de Compliance é o da prevenção de atos lesivos à Administração Pública, praticados por pessoas jurídicas, entende-se claramente que tal Programa deverá ser plenamente capaz de detectar possíveis desvios, antes que estes comprometam irremediavelmente as atividades da Organização que, para tal, se irá valer de Controles Internos realmente eficazes e "condizentes com a natureza, complexidade e riscos das operações por ela realizadas. (RIBEIRO: 2017, p.213)

A Resolução 2554, de 24 de setembro de 1998, do Banco Central do Brasil, por meio do Conselho Monetário Nacional, apresenta os elementos essenciais que deverão conduzir os sistemas de Controles Internos nas instituições financeiras, pelos quais são elas responsáveis e "cujos vetores são perfeitamente aplicáveis ao programa de integridade proposto pelo Decreto Federal 8420/2015” (Idem,p.213).

Tais Controles devem prever, como dispõe o art. $2^{\underline{o}}$ e incisos de I a VII, da referida Resolução e apresentados aqui de forma resumida, a saber: definição de responsabilidades na instituição; a preocupação com possíveis conflitos de interesse entre as atividades dos que compõem a instituição e o monitoramento das áreas sensíveis a tais potenciais conflitos; a identificação e avaliação dos fatores externos e internos suscetíveis de comprometer a realização dos objetivos da instituição; a real efetividade dos canais de comunicação, com a permissão de acessos fáceis, conhecidos dos funcionários, para o registro de informações confiáveis, tempestivas e relevantes, no que se refere às suas atividades e responsabilidades; treinamentos periódicos sobre o Programa; análise sistemática de riscos e monitoramento contínuo dos registros contábeis, para adequada compreensão das transações da Organização, permitindo, assim, que possíveis desvios possam ser prontamente corrigidos. Muito importante é que os sistemas de informações sejam submetidos a testes periódicos de segurança, mormente aqueles utilizados nos setores informatizados.

Lembrar que tais avaliações, com suas respectivas conclusões, deverão ser sempre documentadas e enviadas à Alta Administração, ao 
Setor de Compliance e a outras áreas envolvidas, que deverão se manifestar a respeito das irregularidades encontradas e das medidas tomadas para o saneamento dessas.

Igualmente de real importância, será a criação do chamado Canal de Denúncias, destinado a dar conhecimento, aos órgãos próprios da Organização, dos atos lesivos que forem identificados, de maneira rápida e segura para o denunciante. E para que possa cumprir adequadamente o papel que lhe será atribuído, deverá estar instalado facilmente ao alcance de todos e de qualquer um que observe a prática de qualquer ato em desacordo com a Lei e, consequentemente, com as Práticas da Organização, permitindo total anonimato para o denunciante. Tal Canal de Denúncias deve estar visível, de preferência também no "site" da Organização, permitindo a utilização de variados canais de comunicação, como "contato direto, formulação de cartas e requerimentos, contato telefônico, meio eletrônico", amplamente divulgado entre todos os que pertencem à Organização. "Cumpre ressaltar que os aludidos canais de comunicação devem estar abertos a terceiros que mantêm vínculo jurídico ou comercial relevante com a empresa, não se restringindo apenas ao público interno." (RIBEIRO: 2017, p.216).

Necessário é esclarecer a todos os componentes da Organização, a real natureza desse Canal de Denúncias, que deverá ser entendido como mais um mecanismo de prevenção de possíveis atuações irregulares, ou mesmo ilícitas, com o objetivo não apenas de evitá-las, mas também de corrigi-las, visando que todos trabalhem em um ambiente ético e justo, sem o receio de investigações administrativas e até mesmo policiais. Tais denúncias, feitas com a intenção de fazer-se a coisa certa no seu ambiente de trabalho, não se confunde com a cultura do "dedo-duro" tão presente em nossa cultura, bem como da mesma forma não se confunde com um “denuncismo inescrupuloso”. Tal situação pode ser bastante minimizada, "por meio de processos de educação corporativa e treinamentos sistemáticos quanto ao uso da ferramenta, cumprindo salientar que as garantias legais e regimentais não acobertam os denunciantes que agem com manifesta má-fé." (RIBEIRO: 2017, p.217).

Como não há Organização Empresarial imune a atos de corrupção, mesmo com um efetivo Programa de Compliance, já que os riscos são da natureza dos negócios realizados entre pessoas, o Programa, ao detectar tais atos lesivos, seja pela via do Canal de Denúncias, seja por Monitoramento ou Auditoria Interna ou Externa, passará a cuidar de sua remediação e, sob o pálio da Lei, apresentará aos órgãos próprios da 
Organização - a Alta Administração e/ou o Conselho de Administração -, as medidas corretivas a serem tomadas, as condutas que deve tomar a Organização na informação da existência desses atos, e como os está corrigindo, aos Órgãos Públicos pertinentes ao assunto.

Anteriormente à Lei 12.846/2013, a responsabilidade das pessoas jurídicas de direito público, ou de direito privado prestadoras de serviços públicos, era reconhecida apenas na prestação e qualidade dos seus serviços, responsabilidade essa entendida como objetiva, ou seja, independente de culpa e disposta pelo $\$ 6^{\circ}$ do artigo 37, da Constituição da República, pelos artigos 43 e 931 do Código Civil e pelos artigos 12 e 14 da legislação consumerista (Lei 8078/90). Não se cuidava do relacionamento empresarial de pessoas jurídicas de direito privado com a Administração Pública, o que se constituía em grave omissão legislativa, omissão essa que, no entanto, já não mais existia no ordenamento jurídico de várias administrações estrangeiras.

Eis que, frente aos inúmeros e gravíssimos casos de corrupção empresarial observados em nosso país, nos últimos anos, com repercussão importante na economia de outros países, que, por vez, já nos vinham pressionando para a criação de uma legislação específica, tornou-se mandatório a criação de leis que levassem à responsabilização das Organizações Empresariais, e de seus agentes, nos atos de corrupção aqui e no exterior, a exemplo das várias leis internacionais, como a FCPA (Foreign Corrupt Practices Act, de 1977), da U.K. Bribery Act (Lei Antissuborno do Reino Unido, de 2010), a OECD (Organization for Economic Co-operation Development), OCDE em português: Organização de Cooperação e Desenvolvimento Econômico, em 1960 e outras.

O Brasil, então, em 02 de junho de 1992, apresenta a Lei Federal 8429, a Lei de Improbidade Administrativa, orientada para os agentes públicos, no caso de enriquecimento ilícito (Art.9ํ) no exercício de mandato, cargo, emprego ou função na administração pública direta, indireta ou fundacional; nos atos que causam prejuízo ao erário (Art.10); e nos que atentam contra os princípios da Administração Pública honestidade, imparcialidade, legalidade e lealdade às instituições (Art.11), "aqui também compreendida a lesão à moralidade administrativa. [...] É cediço que a má-fé é premissa do ato ilegal e improbo." (REsp 480.387/SP).

Ao analisar-se a referida Lei, em seu art. $1^{\circ}$ e $\S$ único, entende-se que o sujeito ativo na prática de ato de improbidade é o agente público, 
servidor ou não, enquanto o sujeito passivo é (em uma fusão desses dois dispositivos), verbis:

\begin{abstract}
a Administração Direta, Indireta ou Fundacional de qualquer dos Poderes da União, dos Estados, do Distrito Federal, dos Municípios, de Territórios, de empresa incorporada ao patrimônio público ou de entidade que receba subvenção, benefício ou incentivo, fiscal ou creditício, de órgão público, bem como daquelas para cuja criação ou custeio o erário haja concorrido ou concorra com menos de cinquenta por cento do patrimônio ou da receita anual, limitando-se, nesses casos, a sanção patrimonial à repercussão do ilícito sobre a contribuição dos cofres públicos.
\end{abstract}

Dessa forma, a Lei de Improbidade Administrativa reconhece, portanto, que o agente público, na prática dos atos ilícitos descritos nos artigos 9 e 10 da citada Lei, será responsabilizado subjetivamente, pois, como reconhece o REsp 604.151/RS, verbis: "tanto a doutrina como a jurisprudência do STJ associam a improbidade administrativa à noção de desonestidade, de má-fé do agente público."

Em 03 de março de 1998, surge a Lei sobre os Crimes de Lavagem de Dinheiro, a Lei 9613, alterada posteriormente pela Lei 12.683, de 9 de julho de 2012, com o fito de tornar a antecessora mais eficiente no que tange à persecução penal para os referidos crimes. Trata-se uma lei penal voltada para a pessoa física que utilizar o sistema financeiro para os atos de, verbis:"...disposição, movimentação ou propriedade de bens, direitos ou valores provenientes direta ou indiretamente, de infração penal." (Art. $\left.1^{\circ}\right)$ Em nosso ordenamento, as leis penais pertencem à seara da responsabilidade subjetiva, como sabido.

Permanecia, entretanto, a inexistência de legislação específica no que se referia ao reconhecimento e consequente punição para atos ilícitos praticados por pessoa jurídica, na linha do que dispõe o § 5o do Art. 173, da Constituição da República, verbis:

Art. 173 §5:- A lei, sem prejuízo da responsabilidade individual dos dirigentes da pessoa jurídica, estabelecerá a responsabilidade desta, sujeitando-as às punições compatíveis com a sua natureza, nos atos praticados contra a ordem econômica e financeira e contra a economia popular.

E o próprio texto constitucional invocava, mais adiante, no seu artigo $225 \S 3^{\circ}$, no Capítulo VI, destinado ao meio ambiente, que, verbis: "As condutas e atividades consideradas lesivas ao meio ambiente sujeitarão os infratores, pessoas físicas ou jurídicas, a sanções penais $e$ 
administrativas, independentemente da obrigação de reparar os danos causados." (grifo nosso)

Mais ainda, o legislador em 12 de fevereiro de 1998, com base nos referidos dispositivos constitucionais, edita a Lei 9605, dos Crimes Ambientais, que assim inicia o caput de seu Art. 3ำ, verbis:"As pessoas jurídicas serão responsabilizadas administrativa, civil e penalmente, conforme o disposto nesta lei..." (grifo nosso)

Não obstante não seja o escopo de nosso trabalho discutirmos as implicações penais dos atos ilícitos praticados por pessoas físicas ou jurídicas, vislumbramos a necessidade de maior reflexão quanto à responsabilização penal da pessoa jurídica, em que, como aponta WALKER Jr (2015, p.266), verbis: "Não será a promulgação de leis o elemento de contenção daqueles 'fatores crimógenos', que se instrumentalizam ideológica e dogmaticamente na Criminologia, jamais no Direito Penal."

Por outro lado, a falta de uma legislação que não apenas coibisse, mas prevenisse e punisse, de forma efetiva e eficaz, na seara civil, as pessoas jurídicas envolvidas em atos de corrupção, atos esses cada vez mais presentes na vida brasileira, lesando, muitas vezes irremediavelmente, a Administração Pública do país e atingindo a Administração Pública estrangeira, com a movimentação de somas astronômicas, implicando o Brasil, por seu turno, em pagamento de multas igualmente astronômicas por tais atos criminosos, grande parte deles já previstos em nossa legislação, obrigou-nos à criação de um diploma legal específico - a Lei 12.846, de $1^{\mathrm{o}}$ de agosto de 2013, a chamada Lei Anticorrupção - com vacatio legis de 180 dias, vigente a partir de 29 de janeiro de 2014. Entretanto, como tratava-se de um diploma legal carente de regulamentação, tal falta foi suprida, mas apenas em 18 de março de 2015, com o Decreto Federal 8.420. A responsabilização da pessoa jurídica disposta por essa Lei é objetiva, um marco importantíssimo na seara da responsabilização administrativa e civil da pessoa jurídica, que vem oferecer, sem dúvida, uma efetividade muitíssimo maior a outras leis anteriores e, salvo melhor juízo, mais especificamente à Lei 9613/98, a Lei de Lavagem de Dinheiro, já por nós mencionada linhas atrás.

Cabe chamar a atenção, nesse momento, que, a partir da Lei Federal 12.846/13, Estados e Municípios brasileiros têm-se mobilizado para criar suas Leis anticorrupção, dentro de suas competências 
específicas, e que em vários Estados a Lei já encontra regulamentação, a saber: AL, DF, ES, GO, MA, MT, MS, MG, PE, PR, RN, SC, SP e TO.

O Estado do Rio de Janeiro criou a Lei 7.753, em 17 de outubro de 2017, com vigência em 18 de outubro de 2017, tornando obrigatória a existência de programas de Compliance nas empresas que celebrarem contratos com a Administração Estadual, direta, indireta e Fundacional autarquias, fundações e empresas estatais (públicas ou mistas). E de inconteste importância é o fato de que a adesão ao Compliance passará a ser obrigatória nos contratos firmados com o Poder Público, em todo o Estado do Rio de Janeiro, caso os valores venham a ultrapassar os limites que hoje estão previstos na Lei 8.666/93 na modalidade de contratação via concorrência, ou seja: $\mathrm{R} \$ 650$ mil (para compras e serviços) ou $\mathrm{R} \$ 1,5$ milhão (para obras e serviços de engenharia).

Importante igualmente lembrar que, em 30 de junho de 2016, passou a fazer parte de nosso Ordenamento Jurídico, a Lei Federal 13.303, que dispõe sobre o Estatuto Jurídico da Empresa Pública, da Sociedade de Economia Mista e de suas Subsidiárias, no âmbito da União, dos Estados, do Distrito Federal e dos Municípios, Lei esta, já por nós citada no início do trabalho. Este diploma legal vem, em boa hora, suprir com um novo olhar, um olhar de Integridade, um olhar de Transparência, um olhar de Compliance, um olhar consentâneo com os tempos que correm, no que toca, precipuamente, à prevenção dos atos lesivos à Administração Pública Brasileira e, consequentemente, ao nosso país.

\section{A RESPONSABILIDADE ADMINISTRATIVA DA PESSOA JURÍDICA NA LEI 12.846/13}

Já no seu artigo 1ํㅡ, esta Lei (12.846/13) dispõe sobre a responsabilidade administrativa e civil de pessoas jurídicas, evidenciando, portanto, que não se trata de Lei penal, o que não significa que não apresente reflexos na área penal, pois que, como explicam DAL POZZO et alii :2015,p.19): verbis:

“... a liberdade de participar de atividades que o Estado transfere ao particular ou de fornecer ao Estado bens ou serviços está - pela Lei 12.846/13 e doravante - condicionada a não prática de certas condutas, para que sejam, sob esse ângulo, entendidas como lícitas. (...) as normas da Lei 12.846/13 não contêm proibições expressas, 
pois adotam, em verdade, a mesma estrutura das normas penais. (grifo dos autores)

Continuam os autores, exemplificando sua interpretação, com o artigo 121, do mesmo Código Penal, "Matar alguém”, quando alguém descumprindo essa norma é apenado de 6(seis) a 20(anos) de reclusão, em que "a pena imposta é que dá o conteúdo de proibição à conduta." (Idem: 2015, p.19) A forma adotada pelas nossas leis penais, portanto, volta-se no sentido de promover o cumprimento destas, impedindo, assim, que sejam descumpridas pela sociedade. Reconhecem os autores que estamos, dessa forma, frente ao poder de polícia exercido pelo Estado, raciocínio que podemos aplicar à Lei 12.846/13 que, dotada de tal poder, tem a possibilidade de instituir diversos comportamentos como atos ilícitos, porque lesivos à Administração Pública e que representam verdadeiros atentados aos valores que ela busca tutelar", verbis:

... o patrimônio público nacional ou estrangeiro, os princípios da Administração Pública e os compromissos internacionais assumidos pelo Brasil (Art.5-, caput).(grifo do autor)

A Lei 12.846/13, mesmo com tal interpretação, demonstra que, ao não apresentar tipificação penal própria, para os atos de corrupção praticados pela pessoa jurídica, afasta-se da perniciosa ideia de vingança, tornando-se assim muito mais eficaz no controle de tais atos ilícitos, pois a inscrição da pessoa jurídica no Cadastro Nacional das Empresas Inidôneas e Suspensas (CEIS) e no Cadastro Nacional das Pessoas Punidas (CNEP) já irá significar perda importante do valor da Organização Empresarial no mercado. Mais ainda, poderá esta sofrer a sua dissolução compulsória, por ter tido sua personalidade jurídica utilizada para facilitar ou promover a prática dos atos lesivos, ou mesmo criada para ocultar ou dissimular tais práticas, bem assim quanto às identidades dos envolvidos nesses atos (Art. $18 \S 1^{\circ}$ ), lembrando, por outro lado, que as multas altíssimas que a aguardam, podem permitir tal dissolução na prática, pela total impossibilidade, por vezes, de fazer frente aos enormes valores das multas exigidas pela referida Lei, já que essas podem alcançar até $20 \%$ do faturamento bruto da Organização Empresarial, calculadas, excluídos os impostos, sobre o faturamento bruto do último exercício anterior à instauração do processo administrativo. (Art. 6oㅡ, I, da Lei em apreço). Percebe-se, portanto, que se está frente à mais grave situação a ser enfrentada pela Organização, uma verdadeira Pena de Morte! 
Por outro lado, é interessante o fato de que, acenando esse diploma legal para a atenuação de penas aplicadas a uma Organização que implementar procedimentos efetivos de combate à corrupção, estabelecendo, assim, uma real cultura de conformidade, "começou a alterar, também a perspectiva e a relevância dada ao Compliance, conferindo-lhe uma vertente criminal." (SILVA, 2019)

No que toca à responsabilização da pessoa jurídica na Lei 12.846/13, o Art. 1ํ dispõe, verbis:

Art. 1: Esta Lei dispõe sobre a responsabilização objetiva administrativa e civil de pessoas jurídicas pela prática de atos contra a administração pública, nacional ou estrangeira. (grifo nosso)

Importante assinalar que a Lei não define o que seja Administração Pública Nacional, "exigindo-se a realização de interpretação sistemática de seus dispositivos com outros diplomas legais, conceitos doutrinários e, inclusive, com as razões expostas em seu projeto de lei" (RIBEIRO, 2017,p.37) Entretanto, quanto à Administração Pública estrangeira, ela o faz, verbis:

Art. 5o, V, §1ํㅜ: Considera-se administração pública estrangeira os órgãos e entidades estatais ou representações diplomáticas de país estrangeiro, de qualquer nível e esfera de governo, bem como as pessoas jurídicas controladas, direta ou indiretamente, pelo poder público de país estrangeiro.

Temos na Lei em questão expressamente determinados os sujeitos ativos, que são as pessoas jurídicas, e os sujeitos passivos, que, além dos já estabelecidos na Lei 8429/92, a Lei de Improbidade Administrativa, compreende igualmente a Administração Pública Estrangeira, como se observa da leitura do citado dispositivo.

Ao examinarmos o seu parágrafo único, verificamos que a Lei especifica quais são essas pessoas jurídicas, de forma muitíssimo abrangente e, que tal se dá pela razão que já discutimos anteriormente, ou seja, pela opção do referido diploma legal em restringir-se às áreas civil e administrativa, sem enveredar pela área penal, o que a dispensou de provar dolo ou culpa das pessoas físicas que integram as pessoas jurídicas envolvidas. Dessa forma, temos que a Lei 12.846/13 torna-se a primeira Lei que trata da corrupção das pessoas jurídicas pela vertente objetiva, 
lembrando que as pessoas físicas permanecerão sendo responsabilizadas subjetivamente, como aponta o $\S 2^{\circ}$ do Art. $2^{\circ}$ desta Lei.

As pessoas jurídicas atingidas pela Lei 12.846/13 são, conforme dispõe o citado parágrafo:

... as sociedades empresárias e as sociedades simples, personificadas ou não, independentemente da forma de organização ou modelo societário adotado, bem como a quaisquer fundações, associações de entidades ou pessoas, ou sociedades estrangeiras, que tenham sede, filial ou representação no território brasileiro, constituídas de fato ou de direito, ainda que temporariamente.

Contudo, não se esgota nesse dispositivo a relação das pessoas jurídicas abarcadas por essa Lei, como observamos da leitura do Art. 4º, caput, que dispõe que, em caso de alteração contratual, transformação, cisão, incorporação e fusão societária, subsiste a responsabilidade da pessoa jurídica, que não aquela que foi originalmente responsabilizada. $\mathrm{O}$ $\S 1^{\circ}$ estabelece que o pagamento de multa e reparação integral do dano atinge a todas as situações citadas, restringindo, entretanto, quanto à incorporação e à fusão, pois tanto a multa, como a reparação, deverão ser limitadas até o limite do patrimônio transferido, exceto se comprovados simulação ou evidente intuito de fraude.

Aponta DEMATTÉ (2014, p. 1) para a possibilidade de algumas "perplexidades dogmáticas" quando se trata do pagamento de multa e reparação do dano, ao examinar-se tais obrigações "fora do contexto dos demais preceitos normativos extraídos da Lei 12.846/13" Cuidamos aqui da responsabilidade solidária, como preceitua o $\$ 2^{\circ}$ desse Art. $4^{\circ}$, verbis:

\footnotetext{
Art. $4^{\circ} \S 2^{\mathrm{o}}$ : As sociedades controladoras, controladas, coligadas ou, no âmbito de respectivo contrato, as consorciadas serão solidariamente responsáveis pelas práticas dos atos previstos nesta Lei, restringindo-se tal responsabilidade à obrigação de pagamento de multa e reparação integral do dano causado. (grifo meu)
}

Cabem aqui algumas palavras sobre tais relações societárias, explicitadas nesse parágrafo, lembrando que solidariedade não se presume, resulta da lei ou da vontade das partes, como dispõe o art. 265, da Lei Civil. Percebe-se, assim, que estamos frente a mais uma forma de solidariedade legal, esta inscrita na nova Lei $12.846 / 13$, ao lado das várias outras dispostas em nosso ordenamento jurídico, como no artigo 18 da Lei Consumerista; no artigo 134, do CTN; no art. 2º $\$ 2$, da CLT, ou nos artigos 
680, 942, do Código Civil, a título de exemplo, o que nos fará voltar a esse assunto algumas linhas adiante.

Na relação de controle, retira DEMATTÉ (Idem, p.2) do Art. 1098 do Código Civil e do Art. 243, §2º , da Lei 6404/76 (das Sociedades por Ações) o conceito de sociedade controladora, como aquela que, diretamente ou por meio de sociedade interposta, é titular de direitos de sócio, com o poder permanente e de preponderância nas deliberações sociais, bem assim o de eleger a maioria dos administradores de uma sociedade controlada.

Quando se trata de uma relação de coligação, chama ele a atenção para a sua existência sob duas formas diversas, relacionadas à presença, ou não, de uma sociedade anônima envolvida. Se esta não está presente, a relação de coligação será reconhecida ao possuir uma delas uma participação de $10 \%$ ou mais do capital da outra sociedade, sem que a controle, como dispõe o art. 1099 da Lei 6404/76. Entretanto, caso haja envolvida uma sociedade anônima, a sociedade investidora não controla a sociedade investida, mas detêm ou exerce sobre estão poder de participar nas decisões das suas políticas financeira ou operacional, poder este presumido se a sociedade investidora for titular de $20 \%$ ou mais do capital votante da investida, como disposto no Art. $243, \S \S 1^{\circ}$ e e $4^{\circ}$, da Lei 6404/76.

$\mathrm{Na}$ relação de consórcio, esta é entendida como uma associação de sociedades ou companhias voltadas para um determinado empreendimento, sem personalidade jurídica própria, mas cujo contrato associativo deve ser arquivado no registro comercial de sua sede e publicada a sua certidão, como disposto nos artigos 278 e 279 da Lei 6404/76. Lembra ainda DEMATTÉ (2014,p.2), que esse tipo de consórcio, chamado de "contratual", é diverso dos " 'consórcios societários", que se formam por meio da constituição de uma nova pessoa jurídica (sociedade limitada ou anônima), denominada 'sociedade de propósito específico'(SPE), a qual possui personalidade jurídica e escrituração contábil próprias"

Após essas breves considerações, entende DEMATTÉ (2014,p.3) que a responsabilidade solidária, prevista na Lei 12.846/13,

“deve ser compreendida à luz da própria Lei anticorrupção. (...) "Uma interpretação isolada e literal da disposição legal contida no

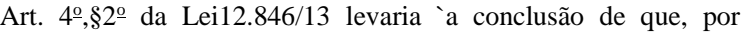
exclusivo critério do órgão ou entidade da Administração Pública lesada, a exigibilidade das obrigações pelo pagamento da multa e pela reparação dos danos poderia recair livremente sobre quaisquer 
sociedades empresárias que tivessem entre si algum tipo de relação societária, (...), bastando que uma delas tivesse incorrido em alguns dos atos lesivos previstos no Art. 5o."

Como exemplo, imagina ele uma holding, com participação em várias sociedades, ela poderia ser chamada para responder integralmente, por uma multa altíssima, em razão de uma sua coligada ter praticado ato ilícito previsto nessa Lei, ainda que ela, a holding, nenhum benefício houvesse auferido. Inversamente, fosse a holding a infratora, qualquer uma de suas coligadas poderia ser chamada a cumprir integralmente o devido, mesmo que não tivesse qualquer relação de interesse com o ato lesivo praticado pela holding. DEMATTÉ (2014,p.3)

Por tais razões, acrescenta, impõe-se a necessidade de que tal hipótese deva ser interpretada "de forma harmônica com os demais dispositivos da própria Lei em que ela se encontra prevista e, sobretudo, com a finalidade econômica e social que inspirou a criação jurídica da Lei Anticorrupção e dos seus institutos. "(Idem, 2014,p.3)

\subsection{O REGIME DA RESPONSABILIZAÇÃO ADMINISTRATIVA OBJETIVA DA PESSOA JURÍDICAA}

Haja vista a pessoa jurídica não apresentar vontade ou consciência, já que sua personalidade jurídica é criação do Direito, não há como lhe reconhecer a presença ou não de culpabilidade, repousando nessa situação a impossibilidade de se nela estabelecer a responsabilidade subjetiva para a prática dos seus atos lícitos ou ilícitos, situação completamente diversa da observada pela pessoa física, como sabido.

Entretanto, o Direito Administrativo Sancionador, reconhecendo tal dificuldade de serem aplicados, de forma integral, aos atos ilícitos da pessoa jurídica, os paradigmas da pessoalidade e culpabilidade, foi buscar na Constituição da República o princípio regulador a ser aplicado, em que se destaca "o princípio da função social da propriedade, do qual é corolário o princípio da função social da empresa, aptos a legitimar um novo horizonte constitucional sobre o sistema de responsabilização de pessoas jurídicas, 'a responsabilidade objetiva corporativa'. (RIBEIRO: 2017, p.42)

O que se propõe é uma vinculação ética da propriedade, em que se exige um novo comportamento, a ser comprovado sob um olhar, agora, 
puramente objetivo, qual seja, "a compatibilidade de sua atuação institucional (da Organização Empresarial) com um determinado padrão legalmente estabelecido, inclusive, para fins de responsabilização." (Idem, p.45)

O objetivo da implantação desse novo modelo de responsabilização é o de transformar, as Organizações Empresariais, em sujeitos proativos na prevenção dos atos nefastos de corrupção, corrupção essa que destrói o tecido social e que se mostra como “... uma moeda composta de dois lados, o agente corrompido, em regra, integrante do setor público e o agente corruptor, em regra, integrante do setor privado. (Idem, p.45)

O sistema brasileiro de responsabilização empresarial contempla dois tipos de responsabilização, ou seja, a responsabilidade ordinária, referente ao desenvolvimento em geral das atividades econômicas empresariais e a responsabilidade extraordinária, aquela encontrada como consequência da prática de atos ilícitos violadores do regramento legal. É exatamente nesse modelo da responsabilidade extraordinária que está posicionado o sistema de responsabilização de pessoas jurídicas disposto pela Lei 12.846/13, a Lei Anticorrupção.

Nesse ponto de nosso trabalho, gostaríamos de discutir um dispositivo da Lei 12.846/13, que reputamos de importância transcendental para a sua real efetividade; que RIBEIRO (2017,p.53), refere como o "ponto central de avaliação no curso do PAR" (Processo Administrativo de Responsabilização); e que DEMATTÉ (2014, p.3) aponta como " $a$ pedra angular normativa da Lei Anticorrupção”.

A Lei 12.846/13 dispõe em seu artigo $2^{\circ}$, verbis:

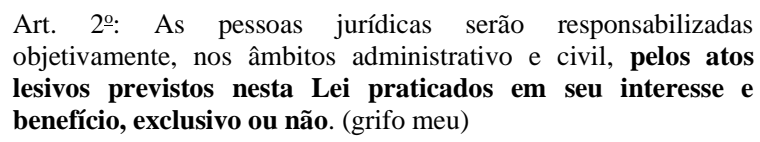

Os atos lesivos no geral, a que o citado dispositivo se refere, encontram-se dispostos no Artigo 5o, da Lei em questão e devem ser entendidos como numerus clausus, pois o regime da responsabilização objetiva das Organizações Empresariais, e disposta por esta Lei, "constituise em exceção no nosso sistema jurídico (tornando) o art. $5^{\circ}$ taxativo e não meramente exemplificativo, como ocorre com os atos de improbidade administrativa, da Lei 8429/92"(DAL POZZO et alii: 2015, p.61). O ponto a que nos referimos acima, está disposto no inciso IV, a alínea " $\mathrm{f}$ " da 
Lei 12.846/13, estendendo a sua abrangência especificamente a licitações e contratos, verbis:

\footnotetext{
Art. 5o, IV, "f": obter vantagem ou benefício indevido, de modo fraudulento, de modificações ou prorrogações de contratos celebrados com a administração pública, sem autorização em lei, no ato convocatório da licitação pública ou nos respectivos instrumentos contratuais ...
}

A Lei estabelece que é atribuição da Administração Pública (Art. 8 a a Art. 15) a demonstração da prática de tais atos ilícitos e o nexo causal entre o ilícito e a atuação direta ou indireta da pessoa jurídica. "O nexo causal consiste na demonstração de que o ato lesivo fora praticado no interesse ou benefício, ainda que indireto, da pessoa jurídica processada. (RIBEIRO, 2017, p.53) É a presença do binômio responsabilidade X proveito, entendido esse último como interesse ou benefício, que estabelece o "liame causal que conecta a prática da infração administrativa à atuação institucional de uma determinada pessoa jurídica". (Idem, p.53). O que irá condená-la é o nexo de causalidade entre o ato lesivo cometido e o ganho que ela, a pessoa jurídica teve! O dano será levado em conta, e com firmeza, na ocasião do término do Processo Administrativo de Responsabilização - PAR - ao cuidar-se da dosimetria da pena. Os valores somar-se-ão àqueles das multas claramente vultosas previstas na Lei, quando podem chegar a até $20 \%$ do faturamento bruto da Organização no semestre anterior.

Impende assinalar que tal acontece de forma diversa da responsabilização objetiva disposta na legislação civilista, quando, como já mencionamos, importa a prática do ato ilícito e o nexo causal presente entre este e o dano ou prejuízo causado. Já sob o pálio da Lei 12.846/13, o que se configura, de forma evidente, é que o nexo causal representa nada mais nada menos, que o elo entre o ato lesivo, incurso no art. 5o da Lei e "a promoção de um benefício ou a satisfação de um interesse da pessoa jurídica a que se pretende imputar a ilicitude do ato..." (DEMATTÉ, 2014,p.3)

Mais ainda, não se trata de estabelecer a responsabilidade objetiva empresarial em qualquer caso de prática de atos ilícitos contra a Administração Pública, é necessário que o nexo causal e suas excludentes sejam analisados segundo os princípios da razoabilidade e proporcionalidade, para que não se transforme a pessoa jurídica "numa 
espécie de seguradora universal da moralidade administrativa." (Idem, p.53)

No caso da responsabilidade entre empresas coligadas, controladas, controladoras ou consorciadas, DEMATTÉ (2014, p.3) chama a atenção para o fato de que, embora a responsabilização seja solidária, como determina a Lei 12.846/13, se qualquer uma delas, verbis:

\footnotetext{
"for atraída para a linha de responsabilização por um ato lesivo praticado por outra pessoa jurídica, com a qual mantenha relação societária, será necessário que tenha havido um benefício em prol ou um interesse satisfeito da solidária que se pretende responsabilizar com o pagamento da multa e/ou a reparação do dano." (grifo meu)
}

Tal raciocínio impõe-se na linha do melhor direito, pois, como já sublinhou o citado autor anteriormente nesse trabalho, em se tratando de tais tipos de empresas, estas precisarão ser tratadas de maneira combinada aos demais artigos da própria Lei, para que se possa de forma justa e ética, de um lado assegurar que a correta punição seja feita e de outro lado que se atenda à finalidade econômica e social da empresa, como entende o próprio texto de nossa Lei Maior.

Lembra ainda, RIBEIRO (2017, p. 53-54) que outro ponto da responsabilidade administrativa objetiva disposta pela Lei 12.846/13, vem demonstrar diferença das mais importantes com a legislação civilista, posto que na Lei Anticorrupção,

o dano não se apresenta como elemento indispensável à configuração da responsabilização, uma vez que a ocorrência efetiva do dano se apresenta como mero exaurimento da infração administrativa, componente esse a ser avaliado quando da dosimetria da pena, nos termos dos incisos II, III e IV do Art. 7 o da Lei. (grifo meu)

Significa dizer, que se o importante na responsabilidade civil objetiva, disposta no Código Civil, é a presença do dano ou prejuízo, material ou moral, sem o quê não há o que indenizar, na responsabilidade administrativa objetiva, disposta na Lei $12.846 / 13$, o imprescindível é a comprovação do nexo causal, expresso pela existência do benefício e/ou interesse obtido e/ou demonstrado pela pessoa jurídica, enquanto o dano causado é entendido como exaurimento da prática do ato lesivo e será avaliado na ocasião da dosimetria da pena, no momento da aplicação das sanções, como preceitua o Artigo 7ํㅡ, caput, I, II e IV, verbis: 
Art. 7ํ: Serão levados em consideração na aplicação das sanções:

I - a gravidade da infração

II -

III - a consumação ou não da infração

IV - o grau de lesão ou perigo de lesão

$\mathrm{V}-\mathrm{o}$ efeito negativo produzido pela infração

VI -

VII -

VIII

As pessoas jurídicas infratoras ainda estão sujeitas a várias outras sanções, como já mencionado anteriormente, ou seja, o de serem inscritas no Cadastro Nacional das Empresas Inidôneas e Suspensas (CNEIS), bem assim no Cadastro Nacional das Empresas Punidas (CNEP), sendo que, nesta última, terão registradas as informações sobre os acordos de leniência, celebrados com fundamento na Lei 12846/13 (arts. 22 e 23) e no Regulamento 8420/12 (arts. 44-47), após a celebração do acordo. Tal somente não acontecerá, se for verificado prejuízo às investigações ou ao PAR.

A Lei 12.846/13 ainda prevê que a pessoa jurídica sancionada administrativamente por atos lesivos praticados contra a Administração Pública, deverá publicar, a suas expensas, o extrato de sentença da decisão administrativa sancionadora, cumulativamente, por três tipos diferentes de publicidade: meio de comunicação de grande circulação em sua área de atuação e de prática da infração e, em não havendo, fazê-lo em área de circulação nacional; em edital afixado no próprio estabelecimento ou em local de sua atividade, de grande visibilidade; no seu sítio eletrônico com destaque na página principal.

Ainda poderá a Organização Empresarial infratora ser alvo de responsabilização na esfera judicial (Arts. 18-21) e, se condenada, poderá perder os bens, direitos ou valores relacionados às vantagens que obteve com os atos lesivos, suspensão ou interdição de suas atividades, "proibição de receber incentivos, subsídios, subvenções, doações ou empréstimos de órgãos ou entidades públicas e de instituições financeiras públicas ou 
controladas pelo poder público por prazo definido na Lei 12.846/13 e até mesmo sofrer dissolução compulsória! Pergunta-se: o que irá restar de seu nome, de seu prestígio, de seu valor no mercado, podendo até a Organização Empresarial deixar de existir?

Acreditamos que, ao tomarem conhecimento de tão duras penas, as Organizações Empresariais pensarão bastante a respeito da prática de atos lesivos contra a Administração Pública, ao mesmo tempo em que irão entender que um Programa de Compliance efetivo será o caminho correto que deverão trilhar. Ademais, perceberão que, certamente, o que lhes custará financeiramente, com a implantação e o correto cumprimento de tal Programa, será infinitamente menor do que as perdas abissais que enfrentarão, caso se envolvam em tais infrações e não tenham um Programa de Compliance efetivo e eficaz, funcionando diuturnamente em sua Empresa.

\section{CONCLUSÃO}

A Lei 12.846/13, nossa Lei Anticorrupção, a Lei da Responsabilidade Objetiva voltada para os atos lesivos à Administração Pública, a Lei que não avalia a subjetividade da prática desses atos, mas se preocupa precipuamente com o benefício e/ou o interesse, auferido e/ou demonstrado, na prática de tais atos, é ainda uma Lei muito nova, que, apesar de regulamentada pelo Decreto Federal 8420/15, apresenta pontos carentes de interpretações mais específicas e, principalmente, de jurisprudência superior pertinente. Entretanto, seu valor no tratamento desses inúmeros atos lesivos, mormente na última década e meia, está representado, principalmente, pela punição severa dos agentes responsáveis, com o retorno de numerário significativo ao país, bem assim, pela aplicação de sanções pesadas às pessoas jurídicas envolvidas em tais atos, situações não observadas até então entre nós.

Por outro lado, o Programa de Integridade (Compliance) efetivo vem demonstrar às pessoas jurídicas, que este consiste na única forma de livrar-se das consequências extremamente danosas a que estarão expostas e que, aplicando este Programa por meio de um trabalho minucioso no interior da Organização Empresarial; atento a todos os órgãos vulneráveis a desvios; com a compreensão e o claro apoio da Alta Direção; realizando um treinamento contínuo de todos os que nela trabalham; apresentando 
controles internos de molde a reconhecer possíveis atos ilícitos; bem como um monitoramento e auditoria operantes e, mais ainda, um código de conduta ética respeitado e um canal de denúncias seguro, estará estabelecendo, claramente, uma verdadeira cultura ética, presente em todos os níveis da Organização.

Dessa forma, entendemos que um novo horizonte se anuncia e que podemos ter a esperança de dias melhores para o nosso país, porque, certamente, estamos vivendo Novos Tempos!

\section{REFERÊNCIAS BIBLIOGRÁFICAS}

BACEN. Resolução 2554, de 24 de setembro de 1998. Dispõe sobre a implantação e implementação do sistema de controles internos. Disponível em:

http://www.bcb.gov.br/pre/normativos/res/1998/pdf/res_2554_v3_P.pdf Acesso em 27 mar 2018.

BRASIL. Constituição da República Federativa do Brasil de 1988. Disponível em http://planalto.gov.br/ccivil_03/constituicao/constituicao.htm Acesso em 27 mar 2018.

BRASIL. Decreto 8420, de 18 de março de 2015. Regulamenta a Lei 12.846 de $1^{\circ}$ de agosto de 2013, que dispõe sobre a responsabilização administrativa de pessoas jurídicas pela prática de atos contra a administração pública, nacional ou estrangeira e dá outras providências, Disp. em:

http://www.planalto.gov.br/ccivil_03/_ato2015-2018/2015/decreto/D8420.htm. Acesso em 27 mar 2018.

BRASIL. Lei 6404 de 15 de dezembro de 1976. Dispõe sobre as Sociedades por Ações. Disponível em http://www.planalto.gov.br/ccivil_03/leis/18429.htm. Acesso em 27 mar 2018

BRASIL. Lei 8429, de 2 de junho de 1992. Dispõe sobre as sanções aplicáveis aos agentes públicos nos casos de enriquecimento ilícito no exercício de mandato, cargo, emprego ou função na administração pública direta, indireta ou fundacional e dá outras providências. Disponível em http://www.planalto.gov.br/ccivil_03/leis/18429.htm. Acesso em 27 mar 2018

BRASIL. Lei 9605, de 12 de fevereiro de 1998. Dispõe sobre as sanções penais e administrativas derivadas de condutas e atividades lesivas ao meio ambiente e dá outras providências. Disponível em http://www.planalto.gov.br/ccivil_03/leis/19605.htm. Acesso em 27 mar 2018.

BRASIL. Lei 9613, de 03 de março de 1998. Dispõe sobre os crimes de "lavagem" ou ocultação de bens, direitos e valores; a prevenção da utilização do sistema financeiro para os ilícitos previstos nesta Lei; cria o Conselho de Controle de Atividades Financeiras - COAF e dá outras providências. Disponível em: http://www.planalto.gov.br/ccivil_03/leis/19613.htm Acesso em 27 mar 2018.

BRASIL. Lei 12.846 , de $1^{\circ}$ de agosto de 2013. Dispõe sobre a responsabilização administrativa e civil de pessoas jurídicas pela prática de atos contra a administração pública, nacional e estrangeira e dá outras providências. Disponível em: http://www.planalto.gov.br/ccivil_03/_ato20112014/2013/lei/112846.htm . Acesso em 27 mar 2018. 
BRASIL. Lei 13.303, de 30 de junho de 2016. Dispõe sobre o estatuto jurídico da empresa pública, da sociedade de economia mista e suas subsidiárias, no âmbito da União, dos Estados, do Distrito Federal e dos Municípios. Disponível em: http://www.planalto.gov.br/ccivil_03/_ato20152018/2016/lei/113303.htm . Acesso em 27 mar 2018.

BRASIL. Superior Tribunal de Justiça. Ministro Relator Luiz Fux. REsp nº 480.387. Data do Julgamento em: 16 de março de 2004. DJ: 24 de maio de 2004.

BRASIL. Superior Tribunal de Justiça. Relator Ministro José Delgado; R.P/Acórdão: Ministro Teori Albino Zavascki. REsp 604.151. Data do Julgamento: 25 de abril de 2006. DJ: 8 de junho de 2006.

DAL POZZO, Antonio Araldo Ferraz et alii. Lei Anticorrupção: Apontamentos sobre a Lei ${ }^{\circ}$ 12.846/13. $2^{\mathrm{a}}$ ed. São Paulo: Contracorrente: 2015.

DEMATTÉ, Flavio Rezende. Responsabilidade solidária exige interpretação harmônica. Revista Eletrônica de Direito Consultor Jurídico. São Paulo: Disponível em: http://www.conjur.com.br/2014mar-28/flavio-dematte-responsabilidade-solidaria-exige-interpretação-harmonica. Acesso em 25 de março de 2018.

DONALDSON, Gordon, 2001 apud HIDALGO, Leni Nunes, 2016.

HIDALGO, Leni Nunes - Tone at the top e tone at the middle e a governança corporativa. In:BRAGA, Reinaldo e SOUSA, Filipe (Orgs.). Compliance na saúde - presente e futuro de um mercado em busca da autorregulação. Revista Diagnóstico. Salvador: Sanar, 2016.

HERMALIN, Benjamin E. 2005 apud HIDALGO, Leni Nunes, 2016.

LUCHIONE, Carlo Huberth; CARNEIRO, Claudio. Compliance e Lei anticorrupção - importância de um programa de integridade no âmbito e no setor público. In: PORTO, Vinicius e MARQUES, Jader (Orgs.). O Compliance como instrumento de prevenção e combate à corrupção. Porto Alegre: Editora Livraria do Advogado, 2017.

MUDROVITSCH, Rodrigo de Bittencourt; NÓBREGA, Guilherme Pupe, A Cultura de Conformidade e a Prevenção no Âmbito Empresarial (Parte 2). Revista Eletrônica de Direito Consultor Jurídico. São Paulo: Disponível em: https://www.conjur.com.br/2019-abr-05/mudrovitschpupe-cultura-conformidade-ambito-empresarial. Acesso em 18 de agosto de 2019.

RIBEIRO, Marcio de Aguiar, Responsabilização administrativa de pessoas jurídicas à luz da lei anticorrupção empresarial. Belo Horizonte: Editora Forum, ltda, 2017.

RIO DE JANEIRO. Lei no 7.753 de 17 de outubro de 2017. Dispõe sobre a instituição do programa de integridade nas empresas que contratarem com a administração pública do Estado do Rio de Janeiro e dá outras providências. Disponível em: https://gov-

rj.jusbrasil.com.br/legislacao/511266335/lei-7753-17-rio-de-janeiro-rj. Acesso em 27 mar 2018.

SERPA, Alexandre. Programas de Compliance - o que você precisa saber. In: In:BRAGA, Reinaldo e SOUSA, Filipe (Orgs.). Compliance na saúde - presente e futuro de um mercado em busca da autorregulação. Revista Diagnóstico. Salvador: Sanar, 2016. 
SILVA, Julia Xavier Rosa da. Extensão de Compliance à Prevenção dos Crimes de Cunho Econômico. Revista Eletrônica de Direito Consultor Jurídico. São Paulo: Disponível em: https://www.conjur.com.br/2019-mar-11/julia-xavier-extensao-compliance-prevencao-crimeeconomico. Acesso em 18 de agosto de 2019.

TIROLS, Jean. 2001 apud HIDALGO, Leni Nunes, 2016.

UBALDO, Flavia Safadi. Lei anticorrupção: a importância do programa de Compliance no cenário atual. In: PORTO, Vinicius e MARQUES, Jader (Orgs.). O Compliance como instrumento de prevenção e combate à corrupção. Porto Alegre: Editora Livraria do Advogado, 2017.

WALKER Jr, James. Criminal compliance e responsabilidade penal. In: ESPIÑEIRA, Bruno; CRUZ, Rogerio Schietti e REIS Jr, Sebastião (Orgs.). Crimes Federais. Belo Horizonte: D’Plácido Editora, 2015. 